\title{
Comunicação equipe-família em unidade de terapia intensiva pediátrica: impacto no processo de hospitalização ${ }^{1}$
}

\section{Communication between families and the health team in a pediatric intensive care unit: impact on the hospitalization process}

\author{
Viviane Hultmann NIEWEGLOWSKI ${ }^{2}$ \\ Carmen Leontina Ojeda Ocampo MORÉ ${ }^{3}$
}

\begin{abstract}
Resumo
Este artigo resulta de um estudo que teve como objetivo analisar o processo de comunicação equipe-família e seu impacto em todos os envolvidos na situação de internação, na perspectiva da Teoria da Pragmática da Comunicação Humana. Buscou-se trazer à tona subsídios para instrumentalizar a equipe, visando um melhor entendimento da comunicação diagnóstica e da hospitalização, favorecendo estratégias de enfrentamento para a mencionada situação. Foi uma pesquisa de base qualitativa, na qual foram realizadas entrevistas semi-estruturadas com 16 familiares de oito crianças internadas na unidade de terapia intensiva pediátrica de um hospital Público de Santa Catarina. A análise dos dados, agrupados em unidades temáticas, evidenciou a presença de uma trama comunicacional multideterminada na comunicação entre equipe de saúde e família, a qual afetava decisivamente 0 processo interacional dos envolvidos. Por sua vez, isto tinha uma repercussão direta na qualidade do trabalho dos profissionais e no maior ou menor sofrimento emocional da família.
\end{abstract}

Unitermos: Comunicação interpessoal. Interações equipe de saúde-família. Unidades de terapia intensiva pediátrica.

\begin{abstract}
This article analyzes the process of communication between the health team and the families, and its impact on those involved in the hospitalization process, from theperspective of thePragmatics of Human Communication theory. The purpose of thestudy isto promote strategiesfor coping with hospitalization by suggesting elements that can providetoolsto thehealth teamsas well asto thefamiliesin order to better understand the diagnosisand the rocess of hospitalization. Semi-structured interviews wereconducted with 16 family members of 8 children admitted to the pediatric intensive careunit in a public hospital in thestateof Santa Catarina in southern Brazil. Theanalysisof the data, grouped into thematic units, demonstrated the presence of a multidetermined communication network with regard to the process of communication between the health team and thefamily, which decisively affected the interaction process in the context of the Pediatric Intensive Care Unit. Consequently, this had a direct repercussion on thequality of the work of the professionalsand on the greater or lesser emotional suffering by thefamily.

Uniterms: Interpersonal communication. Professional-family relations. Pediatric intensivecare units.

\footnotetext{
${ }^{1}$ Artigo elaborado a partir da dissertação de V.H. NIEWEGLOWSKI, intitulada “Unidade de terapia intensiva pediátrica: vozese vivências da família".Universidade Federal de Santa Catarina. 2004

2 Universidade Federal de Santa Catarina, Centro de Filosofia e Ciências Humanas, Pós-Graduação do Departamento de Psicologia. CampusUniversitário, 88010-970, Trindade, Florianópolis, SC, Brasil. Correspondência para/Correspondence to: C.L.O.O. MORÉ.

3 Universidade Federal de Santa Catarina, Graduação e Pós Graduação do Departamento de Psicologia. Florianópolis, RS, Brasil.
} 
A Unidade de Terapia Intensiva (UTI) pode ser considerada um subsistema aberto, com características específicas, e que faz parte de um conjunto de outros subsistemas que conformam o sistema maior, denominado de Instituição Hospitalar. É aberto na medida em que está em constante troca com os demais subsistemas, e que se caracteriza por exigir ajustamentos emocionais e comportamentais de todas as pessoas envolvidas na sua rotina, como das pessoas que, de forma temporária, precisam desses espaços, seja como pacientes ou acompanhantes.

Considera-se que a metáfora que melhor define a dinâmica relacional em uma UTI é "a ponte entre a vida e a morte", que sustenta o contexto comunicacional da mesma, deixando a UTI de ser um apenas um local, em termos espaciais, para se transformar em um contexto "gerador de significados" (Moré\&Macedo, 2006), em que a tensão, angústia e estresse estão sempre presentes como uma mensagem subliminar, afetando diretamente o processo de comunicação que ali acontece.

A revisão de literatura das temáticas "unidade de terapia intensiva pediátrica (UTIP)" e "comunicação equipe-família", no que diz respeito aos processos de comunicação, apresenta-se escassa, principalmente na perspectiva da Pragmática da Comunicação, que chama atenção para os efeitos da comunicação no comportamento humano. Ao analisar as características peculiares do contexto da UTIP, observa-se que o processo de comunicação é afetado por uma série de eventos decorrentes do processo específico de internação, que geram uma trama comunicacional na qual tanto a equipe como a família podem ficar presos, impossibilitando os caminhos de uma comunicação efetiva. médico e paciente, assim como entre médico e família, não teve muitos progressos desde que se iniciou a discussão sobre a comunicação de diagnóstico aos pacientes e familiares, sendo que há a necessidade de mudanças, em nível emocional, por parte destes profissionais. Gauderer (1987), por sua vez, aponta que o "medo" da morte, por parte da equipe de saúde, faz com que seus integrantes se voltem para as questões orgânicas e deixem de lado os aspectos emocionais, pois, senão, teriam que se deparar com suas próprias questões emocionais.
A dificuldade de comunicação da equipe com a família também se relaciona com o fato de que, para 0 médico, a morte do paciente simboliza o fracasso profissional (Gauderer, 1987). Assim, à medida que a criança vai apresentando piora no estado de saúde, há uma crescente dificuldade de estabelecer a comunicação com a família.

Estes aspectos mencionados, somados às características peculiares de uma UT, deram as bases para o objetivo do trabalho realizado, que foi o de analisar o processo da comunicação equipe-família em uma UTIP e seu impacto nos envolvidos na situação de internação, sob a perspectiva teórica da Pragmática da Comunicação Humana.

Peculiaridades da unidade de terapia intensiva pediátrica

As primeiras pesquisas so bre UTIP foram datadas em 1980, nos Estados Unidos, e relatavam sobre sintomas de estresse, ansiedade e depressão apresentados pelos familiares, os quais eram gerados pela internação da criança, sendo que as injeções, os sons de alarme do monitor e a batida do coração no monitor foram apontados por mães como os eventos mais estressantes (Board \& Ryan-Wenger, 2002). Complementando os dados anteriores, Miles, Burchinal, Holditch-Davis, Brunsse e Wilson (2002) e Noyes (1998) destacam queo maior estresse está relacionado também com a aparência das crianças, alteração na função parental e ambiente com muito barulho.

Além destes eventos, quando a criança é internada na UTIP, somam-se às preocupações e estressores inerentes à hospitalização a restrição de horários de visitas, as dificuldades de comunicação com a equipee a idéia de que a UTI tem relação com a morte, bem como a incerteza gerada por esta idéia. Lemos e Rossi (2002) realizaram um estudo etnográfico com dezessete pacientes admitidos em um Centro de Terapia Intensiva (CTI) e seus familiares. Pode-se perceber que a internação nesta unidade gerou um significado a priori, vinculado ao desconhecimento eà morte, e que a alta significou 0 retorno à vida.

Cabe destacar a pesquisa de Noyes (1999) que aponta que o maior impacto para as mães ocorre imediatamente após a internação das crianças em UTIP. 
A partir da situação de internação, instala-se um momento de crise e "a família precisa reorganizar-se rápida e eficientemente, modificando sua organização habitual para uma estrutura de crise" (Rolland, 2001, p.382). Nestes momentos, Bousso e Angelo (2003) apontam que o essencial para os membros das famílias é a vida da criança e a preservação da unidade familiar. Por sua vez, a hospitalização pode trazer implícita também a quebra da rede familiar, em todos os sentidos, incluindo a distância física, produzindo ausência da criança e/ou ausência de um dos membros adultos da família, podendo acarretar uma ruptura da estrutura, de forma momentânea ou definitiva. Portanto, na internação hospitalar, os vínculos afetivos e sociais são testados em seu grau de sustentabilidade (Nieweglowski, 2004).

Estabilizada a crise inicial, Noyes (1998) coloca que os estressores continuam a afetar os pais, eas respostas habituais a uma situação estressante costumam não funcionar mais, causando alteração do comportamento. Os pais devem enfrentar a crise, modificando sua representação dos eventos e utilizando novas estratégias de adaptação. Spear, Leef, Cpps e Locke (2002) chamam a atenção para a forma de enfrentamento, que é bastante influenciada pelo nível de estresse, e também para a presença de sintomas depressivos. Se as estratégias de enfrentamento não são efetivas, podem exacerbar problemas, afetando a qualidade de vida de todos os envolvidos. Mitchell, Courtney e Coyer (2003) verificaram que a principal característica destas famílias é a incerteza, reduzindo a habilidade de enfrentar os estressores.

A ameaça de perda da criança também é um aspecto que pode dificultar a ação das famílias no enfrentamento da situação de crise, porém, os pais não costumam falar abertamente sobre a possibilidade de morte. Esta situação infringe o ciclo vital da família, pois é considerada uma perda prematura, fora de hora. "A morte de um filho, frustrando as expectativas geracionais, é talvez a perda mais dolorosa para umafamília, uma vez que ela reverte à ordem natural" (McGoldrick \& Walsh, 1998, p.57). À medida que existe a ameaça de perda da criança, McDaniel, Hepworth e Doherty (1994, p.234) apontam que "... os membros da família, com freqüência, concordam veladamente em evitar discussões sobre a morte. Isto pode ser útil para manter a esperança e o otimismo, mas evita o planejamento e a comunicação franca". Portanto, asfamílias que possuem um membro em UTIP, além de estarem expostas a diversos estressores, são constantemente provocadas a refletir sobre a morte.

Cabe ressaltar que as dificuldades pelas quais a família passa no processo de internação da criança refletem-se no relacionamento com a equipe, 0 que pode ser minimizado a partir do momento que a mesma assume uma postura interdisciplinar (Crepaldi, 1999), permitindo aos profissionais envolvidos o compartilhar das dificuldades e, conseqüentemente, viabilizando a resolução de problemas em conjunto. Ou seja, os diversos profissionais podem dividir a tarefa de informação do quadro clínico da criança, de acordo com o estado emocional de cada um, no momento do contato com a família. Para isto, torna-se pertinente para a equipe conhecer as fases do processo de luto propostas por Klüber-Ross (1996), pelas quais a família pode passar, a fim de melhor compreender a forma de agir no momento de crise da família. As fases propostas por esta autora compreendem: negação, na qual o paciente e/ou a família, ao receberum diagnóstico com prognóstico ruim ou até uma notícia de óbito, lida com a situação negando o fato, sendo que esta maneira de vivenciar o recebimento da notícia está bastante relacionada com a forma como a mesma foi dada; raiva, que pode estar relacionada com os sentimentos de impotência e falta de controle sobre a própria vida; barganha, na qual o paciente e/ou familiares tentam um "acordo" para adiar o desfecho inadiável, ou remediar o diagnóstico, podendo estar relacionada com aspectos de culpa ligados à doença; depressão, na qual surge 0 sentimento de perda, em diversos níveis: perda do corpo, das finanças, da família; ou seja, seria o estado de preparação para a perda de todos os objetos amados; e aceitação, que é considerada uma fase bastante difícil para a família, na qual o paciente, muitas vezes, silencia-se.

0 conhecimento destas fases e de suas peculiaridades, por parte da equipe, contribui para tornar 0 momento de contato com a família menos tenso, propiciando uma comunicação mais efetiva, fazendo com que a família sinta-se mais segura e a relação com a equipe se fortaleça (Borges, Cosmo, Figueiredo \& Vianna, 2004).

0 conjunto destes aspectosestáintrinsecamente relacionado com a comunicação equipe-família, na qual 
a linguagem técnica dos profissionais pode dificultar a compreensão dos fatores ligados à hospitalização. Assim, a orientação a estes familiares de forma mais clara, e em uma linguagem acessível, poderia diminuir a ansiedade, os medos e preocupações dos pais (Aragão, Weiss \& Aquino, 1993), contribuindo, por sua vez, na eficácia das ações da equipe.

Teoria da pragmática da comunicação e seus axiomas

0 processo de comunicação humana envolve uma complexidade de aspectos, tais como conteúdo, forma e linguagem, que se presentificam em todo momento nos processos inter-relacionais. Além do aspecto da significação implícita na linguagem, a análise da pragmática da comunicação nos auxilia a pensar a respeito do efeito da comunicação no comportamento humano.

Segundo Watzlawick, Beavin e Jackson (193), constantemente as pessoas enviam e recebem uma diversidade de mensagens, sejam elas pelos canais verbais ou não verbais, e as mesmas necessariamente modificam ou afetam umas às outras. Quando duas pessoas interagem constantemente, reforçam e estimulam o que está sendo dito ou feito, de tal forma que o padrão de comunicação entre os participantes de uma interação define o relacionamento entre eles. Observa-se, assim, que a importância das mensagens não está vinculada somente à questão de comunicar algo, mas também, e especialmente, à influência que ela exerce no comportamento e nas atitudes das pessoas em interação.

A Teoria da Pragmática da Comunicação Humana, proposta por Watzlawick et al. (1973), afirma que a comunicação afeta o comportamento, tendo implicações fundamentais nas relações interpessoais. Dizem eles: "Atividade ou inatividade, palavras ou silêncio, tudo possui valor de mensagem, influencia os outros, e estes outros que, porsua vez, não podem não responder a essas comunicações, estão, portanto, comunicando também" ( $p .45)$. A teoria mencionada pressupõe cinco axiomas que delineiam o processo de comunicação, que são:
1) Não se pode não comunicar - alude-se aqui a um aspecto fundamental da comunicação: sempre estamos nos comunicando, seja com gestos, posturas ou tom de voz (por exemplo, ficar em silêncio é uma forma de comunicação);

2) Toda comunicação tem um aspecto de conteúdo eum aspecto de comunicação, detal modo que o segundo classifica o primeiro eé, portanto, uma metacomunicação. Segundo os autores, "uma mensagem, seja ela verbal ou não, não só transmite informação, impõe um comportamento" (p.43).

Estes dois aspectos podem ser congruentes ou incongruentes. Um exemplo em que 0 aspecto de conteúdo é qualificado pela metacomunicação é quando a mãe afirma que ama o filho, ou com um gesto de alegria, ou de tristeza. Isto é, os atributos presentes na metacomunicação estarão sempre vinculados, em termos de significação, à compreensão do conteúdo.

3) Anatureza deuma relação está na contingência de pontuação das sequêencias comunicacionais entre os comunicantes. Segundo Watzlawick et al. (1973), uma série de comunicações pode ser vista como uma seqüência ininterrupta de trocas, sendo que essa pontuação organiza eventos vitais para a interação. Elas não são vistas como boas ou ruins pelos autores, mas chamam a atenção para sua existência e para como elas definem as relações entre as pessoas. Um exemplo de seqüência seria quando uma mulher, ao ser questionada por um estranho, sempre olha primeiro para o marido. Geralmente estas seqüências, para os outros, passam despercebidas, ou não são tidas em conta nos processos comunicacionais.

4) Os seres humanos se comunicam digital e analogicamente. As palavras, que são as que constituem a comunicação digital, são sinais arbitrários que se manipulam de acordo com a sintaxe lógica da linguagem. Por sua vez, segundo o autor acima, a comunicação analógica é toda comunicação não verbal que acontece por meio de postura, gesto, expressão facial, inflexão de voz e cadência das palavras, e qualquer outra manifestação não verbal de que o organismo seja capaz, assim como as pistas comunicacionais infalivelmente presentes em qualquer contexto em que uma interação ocorra. Este axioma tem como referência os trabalhos de Gregory Bateson, na década de 1960, com a comu- 
nicação em famílias que apresentavam um membro esquizofrênico, o que o levou a postular o conceito de duplo vínculo, que se caracteriza pelo processo de anulação da comunicação presente nas mensagens, tanto no aspecto do conteúdo, como na metacomunicação, gerando confusão e ambigüidade no receptor da mensagem.

Cabe lembrar que toda comunicação tem um conteúdo e uma relação, e estes dois aspectos não só existem lado a lado, mas se complementam em todas as mensagens, sendo que ambos comunicam. 0 aspecto de conteúdo tem toda a probabilidade de ser transmitido digitalmente, ao passo que 0 aspecto relacional será predominantemente analógico em sua natureza e, portanto, sempre haverá margem para diferentes interpretações.

5) Todas as permutas comunicacionais ou são simétricas, ou complementares, segundo se baseiem na igualdade ou na diferença. As relações podem ser descritas baseadas na igualdade ou na diferença. A interação simétrica é caracterizada pela igualdade e a minimização das diferenças entre os participantes da comunicação, e a interação complementar baseia-se na presença de diferenças entre eles. Assim, temos como exemplo de relações complementares aquelas existentes entre mãe e filho, médico e paciente, professor e aluno.

Entende-se que trazer à tona o processo de comunicação família-equipe durante a internação em uma UTIP, objetivo deste trabalho, torna-se relevante quando utilizado para analisar o processo relacional a partir das mensagens verbais ou não verbais, na medida em que possibilita o melhor reconhecimento do impacto do processo de internação.

Deste modo, observa-se que existe uma série de fatores pertinentes, tanto no sistema familiar, quanto no sistema dos profissionais da saúde, que irão permear a comunicação e influenciar diretamente a forma pela qual as famílias compreenderão a evolução do quadro clínico e a alta da criança. Além disso, cabe ressaltar a afirmação de Board e Ryan-Wenger (2003), segundo a qual uma boa comunicação entre equipe de saúde e família também proporciona benefícios para a criança enferma, protagonista principal de um contexto deUTIP.

\section{Método}

0 estudo caracterizou-se por ser exploratório, descritivo e com análise qualitativa dos dados. A opção pelo estudo qualitativo deu-se na medida em que se buscava a construção do significado das ações dos envolvidos no contexto da pesquisa.

Fiese e Bickham (1998) recomendam o uso da pesquisa qualitativa para investigarquestões referentes à criança e à família, tendo o potencial de fornecer grandes contribuições para a área de Psicologia Pediátrica.

\section{Procedimentos}

A pesquisa teve início a partir das autorizações dos comitês de Ética, da Instituição de Saúde e da Instituição Educacional (Universidade Federal de Santa Catarina). 0 instrumento para a coleta de dados foi uma entrevista semi-estruturada. Todas as entrevistas foram gravadas e transcritas na íntegra, sendo que os nomes dos participantes foram preservados, com a utilização de nomes fictícios.

\section{Participantes}

Participaram da pesquisa oito famílias de crianças internadas na UTIP, sendo entrevistados dois membros de cada uma delas: um era o próprio acompanhante, e o outro era um representante da família na qualidade de visitante da criança, perfazendo um total de dezesseis pessoas. 0 critério para participação da pesquisa era o de ser membro da família da criança. A proposta de entrevistar dois membros da família possibilitou aos pesquisadores obter, a partir de relatos singulares, perspectivas diferenciadas frente à situação de internação, ampliando a compreensão desta realidade. Os familiares que permaneciam no hospital para acompanhar a criança e que possuíam histórico de passagem ou internação em UTIP não foram incluídos na pesquisa, sendo este o único critério de exclusão.

Dos dezesseis participantes, dez encontravam-se na faixa etária entre 21 e 30 anos. Doze entrevistados possuíam o primeiro grau incompleto. Em relação ao grau de parentesco, houve a participação de uma tia, 
uma avó, e o restante constituiu-se de pais e mães. Estas, em sua grande maioria (sete das oito participantes), não trabalhavam fora de casa. Os pais diferenciavam-se em suas profissões, sendo a atividade predominante 0 trabalho na lavoura (três dos seis participantes).

\section{Resultados e Discussão}

Os dados foram analisados com base na Análise de Conteúdo horizontal, proposta porBardin (1977). Esta consiste em uma transformação dos dados brutos do texto, por regras previamente estabelecidas, atingindo um conteúdo representativo do material analisado. Assim, foram estabelecidas quatro unidades temáticas, cuja nomeação surgiu da junção da análise dos dados e da proposta da teoria da pragmática da comunicação, sendo elas: 1) Comunicando diagnósticos e procedimentos; 2) As expectativas na comunicação equipe-família; 3) A comunicação e a sustentação das interações hierárquicas e de submissão; 4) A comunicação e o processo de metacomunicação equipe-família.

Estas unidades evidenciam, na complexidade do processo comunicacional entre família e equipe, certas regularidades comunicacionais, que se complementam e se afetam recursivamente. Acredita-se que estas temáticas se somam à diversidade de aspectos que convergem no processo de internação em uma UTIP, e que, em seu conjunto, determinam diferentes níveis de impacto, tanto na equipe, como na família. Ao falar de impacto, alude-se ao conjunto de reações afetivas e comportamentais decorrentes do processo de internação em UTIP, que estariam afetando as relações familiares e, por conseqüência, as relações da equipe.

\section{Comunicando diagnósticos e procedimentos}

Entende-se que o processo de comunicar diagnósticos e procedimentos, por parte da equipe, constitui um parâmetro poderoso de referência para a família que tem uma criança internada em uma UTIP. Isto dá as bases para o que se denomina de processo hermenêutico, que é concomitante ao anterior e caracteriza-se pela constante interpretação das palavras, gestos, posturas e silêncios da equipe, por parte dos integrantes da família, na contínua e angustiantebusca

116 de sentido e significação para a situação de crise imposta pela doença. A partir da inter-relação destes processos é que se sustentam as diversas reações afetivas e comportamentais da família, que, por sua vez, terão uma ressonância direta na equipe, e marcarão os rumos do processo comunicacional entre ambos os sistemas.

Estes aspectos, relacionados à percepção do sofrimento do filho, ficam evidentes na fala do pai de Luana:

... éde vêo sofrimento dela ali... éde vêo sofrimento que a gente olha e sente... tá loco... daí os médicos falaram que ela tá sofrendo... porque ela não sofria... vê 0 sofrimento dela ali... é muito grande... daí os médicos falaram que ela tá sofrendo mesmo, ela leva mais de 20 picadaspordia, deagulha... vêosdedos, osdedinhosdela na mão tão tudo picado... .

A descrição da tia de Guilherme complementa o depoimento anterior, ao afirmar que: "Quando euviele assim... alisem semexersabe...éuma sensação horrível... acho que não tem sensação pior...". Em acréscimo, o mesmo tipo de sentimento pode ser verificado na fala do pai de Mirela: "Difícil pra mim éver a criança cheia deaparelhos lá... pode morrer ou podesobreviver...".

Associados a estas descrições, que evidenciam o impacto inicial, existem outros aspectos, como a comunicação entre os pais de diferentes crianças internadas na UTIP, gerando um processo de comparação do estado de saúde do filho com os outros, o que é considerado pelos pais como um dificultador. Os pais apresentam a necessidade de comparar a sua criança com as outras na tentativa de compreender o estado de saúde do próprio filho. Isto vai ao encontro dos achados da pesquisa de Bousso (1999), que considera a comparação com os outros casos uma estratégia que a família utiliza para buscar uma causa e justificativa para 0 acontecido com o seu próprio filho.

Estas foram situações reais de diálogos que acontecem nesse contexto, e que constituem uma trama comunicacional para as quais, muitas vezes, a equipe não está preparada, pois são dilemas humanos que ultrapassam a fronteira da profissão e da formação. Mas os membros da equipe precisam lidar estes dilemas, principalmente a partir da perspectiva pessoal, no sentido de utilizar o bom senso ou a sensibilidade que a experiência de vida lhes proporcionou.

Cabe aqui chamar atenção para a estreita relação entre o estado emocional e o processo comunicacional 
dos envolvidos, que são aspectos que se afetam mutuamente, gerando um contexto peculiar para o processo hermenêutico inevitável, tanto por parte da família, como da equipe, no qual se sustentam todos os diálogos sobre comunicação diagnóstica e procedimentos.

A equipe precisa estar consciente deste momento vivenciado pelas famílias, que as incapacita para melhor absorver as informações repassadas pelos médicos, sendo que as mensagens podem ser compreendidas e interpretadas de diferentes formas. Assim, este fato pode fazer com que os familiares deturpem, bloqueiem ou neguem as informações, fazendo com que eles próprios repitam as mesmas perguntas diversas vezes.

Ter clareza de que é impossível não comunicar, primeiro axioma da Pragmática da Comunicação (Watzlawick et al. 1973), deveria ser um trabalho de reflexão da equipe de saúde, pois constitui um dos pontos nodais para trabalhar dilemas humanos de maneira mais fundamentada no contexto profissional. Isto quer dizer que se faz necessário um processo de reflexão constante sobre como esses dilemas extremos, vivenciados em uma UTIP, afetam o profissional da equipe em termos pessoais para, a partir daí, descobrir melhores estratégias de enfrentamento destas situações, em termos comunicacionais, podendo, deste modo, efetivamente acolher o paciente e sua família.

\section{As expectativas na comunicação equipe-família}

A evolução da doença da criança gera expectativas com relação à alta da UTIP. Cabe à equipe médica informar a evolução do quadro da criança e a possibilidade de alta da unidade. A comunicação à família, na instituição onde foi realizada esta pesquisa, acontecia nos momentos de visita, sendo esclarecidas as dúvidas, quando necessário. A partir desta comunicação, os familiares criavam expectativas com relação à forma pela qual a criança sairia da unidade:

Eu tava esperando que ela melhorasse pra nós levar embora deuma vez. Não tirarela deoutra forma... isso aí queeu penso. A gentereza para quenão aconteça. Mas o destino da vida da gente só quem sabeéDeus né? Eu não sei maiso que pensar porque... a gente podeesperar o melhoragora como o pior.Só isso queeu posso pensar... (pai de Mirela).
Os pais de Mirela não conheciam os sintomas e o prognóstico da doença antes da entrada da filha na UTIP. O desconhecimento dos sintomas da doença grave fez com que os acompanhantes das crianças manifestassem momentos de incerteza, reduzindo a capacidade de enfrentar a situação de maneira menos prejudicial. Mitchell et al. (2003) confirmam que a falta de familiaridade com os sintomas da doença aguda pode dificultar o enfrentamento da situação de crise. A família, nestes casos, assumia uma postura mais passiva, não realizando questionamentos, aguardando sempre uma orientação da equipe, que conduzia a ação dos seus integrantes, sendo esta uma situação geradora de muita ansiedade.

Nas famílias de Guilherme, Eduardo e Gabriel, percebeu-se que os médicos passaram dados de realidade do estado de saúde da criança e que, apesar da gravidade, alguns familiares se mantiveram esperançosos. Klüber-Ross (1996) aponta que, a partir do diagnóstico, os familiares passam por diversas fases, que caracterizam o início do processo de elaboração do luto. Verificou-se que estas famílias encontravam-se na primeira fase, ou seja, de negação. Nesta, os familiares tendem a negar a gravidade do diagnóstico, mantendo a esperança da cura:

... a médica disse pra mim: 'o quadro deleainda égrave, porque foi um acidente feio', mas a gente tem que acreditar, né? Agentenão podepensarno pior... (mãe de Guilherme).

Osmédicosfalaram pra mim... pra mim elesfalaram que eletem pouca chancedevida. Mas eu tenho esperança (pai de Eduardo).

Os pais de Manoela encontravam-se na fase de raiva; a família da Graziela, na fase da aceitação, e a família da Luana, na fase de depressão (Klüber-Ross, 1996). Constatar e compreender o momento no qual as famílias se encontram possibilita à equipe de saúde estabelecer uma comunicação com a mesma a partir das características de cada fase, evitando dificuldades de relacionamento.

A ameaça de perda da criança foi uma expectativa que as famílias criaram diante das conversas que eram estabelecidas ao longo da internação na UTIP. Quando a criança encontra-se fora de possibilidades terapêuticas, ou seja, quando não há mais cura, a família é avisada de que a criança apresenta-se em fase terminal. 
Durante a realização desta pesquisa, nenhuma criança chegou a esta fase, conforme investigação no prontuário médico. Porém, a incerteza com relação ao quadro clínico da criança e a falta de informações concretas foram permeando a construção de um prognóstico desfavorável, como no caso da família de Mirela:

... veio (a médica) falar pra nóis que já não tinha mais cura né? equeessa doença dela éforte... coisa quefalaram pra nóis que era fraquinha, que ia ter cura né? Então ela deu pouca esperança pra gente agora... foi um choque pra nóis...então o quea gentevaipensar... (pai de Mirela).

As dificuldades no que se refere à comunicação equipe-família também surgiram noscasosem que não havia evolução do quadro clínico da criança, restringindo a informação médica a "o quadro apresenta-se estável", ou quando houve necessidade de comunicar a piora do quadro, sendo estas situações de muita ansiedade para a família. No mesmo sentido, a imprevisibilidade do diagnóstico também causou desconforto à equipe de saúde, o que ficou evidenciado nos contatos desta com os familiares na sala de espera e dentro da unidade, ou até mesmo pelos diálogos estabelecidos entre os próprios profissionais da saúde. Percebia-se, por parte da equipe, a dificuldade de contato com as famílias, em termos de comunicação, explicitada na falta de palavras acolhedoras, ou em comportamentos que evitavam o diálogo a respeito. Isto exemplifica claramente 0 que, na teoria da comunicação, se denomina de seqüência ininterrupta de trocas de mensagens (Watzlawick et al., 1973), sendo que essa seqüência organiza eventos vitais para a interação, percebidos pela família no contexto daUTIP.Os eventos eram constantemente decodificados e/ou interpretados pela família, sendo geradores de angústia ou estresse para a mesma.

Cabe destacar que o ambiente da UTIP exige concentração, por parte dos profissionais, para a realização do cálculo preciso das medicações, agilidade na tomada de decisões, cuidado e delicadeza em suas ações. Eles se voltam para uma série de detalhes que são imprescindíveis para a manutenção da vida dos pacientes, focando sua atuação em aparelhos, procedimentos e papéis, não sendo desafiados, na sua prática, para o desenvolvimento de habilidades de melhor comunicação com a família em situação de internação. Além disso, a luta dos profissionais contra a morte pode 118 trazer conflitos pessoais, desencadeando ansiedade $\mathrm{e}$ depressão (Meleiro, 1998), e estremecendo o relacionamento com as pessoas que circulam na UTIP.

Desta forma, os profissionais, além de conviverem em um ambiente tenso e permeado pela pressão de salvar vidas, também vão se acostumando a ouvir o silêncio daUTIP e, quando os pais destas crianças entram na unidade questionando, chorando ou reclamando, alguns não compreendem, não sabem como lidar, 0 que perguntar e o que responder; enfim, o que fazer diante de tanto sofrimento.

Na perspectiva da teoria da comunicação, nessa série de fatores que convergem na trama comunicacional, chama-se atenção para a congruência entre a linguagem digital (as palavras) e a analógica (aspecto não verbal presente em qualquer tipo de comunicação digital). Cabe apontar que a família, impactada pela série de eventos, conforme apontado acima, bloqueia aescuta do significado das palavras e busca pistas comunicacionais no aspecto analógico da comunicação, ou seja, em gestos, posturas, observação dos comportamentos da equipe de saúde - privilegiando, de certo modo, a forma como é passada a informação e não 0 seu conteúdo.

Acredita-se que a busca de congruência entre forma e conteúdo das informações que a equipe comunica deveria ser outro item importante a ser pensado e refletido pelo conjunto dos integrantes da mesma, pois isto oferece estratégias comunicacionais, assim como auxilia na melhor compreensão da escuta da família, no sentido de ver suas reações como um processo próprio deste grupo, e não de ataque ou recriminação ao trabalho da equipe, como muitas vezes eram percebidas pela mesma.

A comunicação e a sustentação das interações hierárquicas e de submissão

Tendo como referência o quinto axioma da teoria da comunicação (Waztlawick et al., 1973), que chama atenção para as permutas comunicacionais, assinalando que as mesmas podem ser baseadas na igualdade ou na diferença de posições, especificamente no contexto hospitalar, observou-se a presença de interações equipe-família baseadas na diferença e na complementaridade.

Na pesquisa, isto ficou evidente na família de Manoela, no momento em que o pai tentou questionar 
o médico com relação aos procedimentos realizados com a filha, e este solicitou que o pai não fizesse muitas perguntas:

... em vez devocêreceberuma resposta deânimo, recebe uma agressão... quer dizer... 'nósaqui vamosfazercomo eu acho quetem quefazer... o senhor paredetá fazendo tanta pergunta... nós sabemos como é que tem que proceder, como équeé...' nósvamossalvar'... eu não estou dizendo que vão querer matar a minha filha, eu estou dizendo queeu quero saber... eu pergunto porquea gente tá tenso, tá nervoso...

A afirmação acima demonstra que a comunicação médico-paciente está permeada pela dificuldade de falar sobre estados graves e também sobre a morte, exigindo mudanças por parte da equipe, em nível emocional (Bowen, 1991). 0 falar sobre a morte envolve também refletir sobre suas próprias perdas, dificuldades e resistências, o que dificulta ainda mais a comunicação destes profissionais com seus pacientes e respectivos familiares.

Entende-se que a necessidade de um saber especializado gera, porsi só, um contexto de interações em que a diferença é a tônica, e que se manifesta concretamente no processo comunicacional, revelando a presença de relações hierárquicas e de submissão. Este é outro aspecto importante ao qual os profissionais da equipe devem estar atentos e conscientes, no sentido da sua utilização em situações em que se faz necessário. Ou seja, conhecer e compreender estes aspectos traz aos profissionais melhores subsídios para lidar com famílias em momentos de crise, nos quais as emoções estão exacerbadas, ficando em segundo plano a racionalização para a comunicação com o outro.

\section{A comunicação e o processo de metacomunicação equipe-família}

Complementado a unidade temática anterior, observou-se que as mensagens, além de transmitir uma informação por seu conteúdo, impõem um comportamento e, geralmente, a reação comportamental é resultado da metacomunição sempre presente em uma mensagem (Watzlawicket al., 1973). No contexto da UTIP, a equipe se defronta constantemente com a incerteza das possibilidades de vida da criança e, ao comunicar informações, seja de diagnóstico ou de procedimentos, porintermédio da metacomunicação, acabam desconfirmando crenças, saberes e sentimentos presentes nos familiares. Isto fica evidente no depoimento do pai de Mirela, que ressalta que a equipe também deve estar atenta às variações emocionais dos pais, para que não passem informações em momentos inadequados:

... você pode vê que qualquer coisinha ela tá se emocionando... ela chora... isso a gente vê que ela tá bem abalada mesmo. Então a gentetem quecuidar né? não équalquernotícia quepodepegaredarassim. Então isso ai éfalta do quê? 0 médico tinha queverisso também... não só cuidar lá de dentro... tem que cuidar ali fora também....

0 que é metacomunicado tem um efeito particular em cada indivíduo. 0 processo de metacomunicação, por não estar traduzido em palavras, provoca os mais variados impactos. A família começa a fazer uma leitura própria da metacomunicação da equipe, diante da necessidade de preencher aquilo que não é falado.

Por sua vez, evidencia-se como a comunicação pode ter o efeito da "desconfirmação do outro" - neste caso, dos sentimentos diante do dilema humano vivenciado. Cabe chamar atenção para o fato de que este assinalamento não aponta condutas certas ou erradas da equipe; pretende-se, sim, resgatar a importância desta análise para criar ou pensar melhores estratégias de comunicação entre a equipe e a família.

Sabe-se que a dificuldade de comunicação da equipe com a família também se relaciona com o fato de que, para o médico, a morte do paciente simboliza o fracasso profissional (Gauderer, 1987). Assim, à medida que a criança vai apresentando piora no estado de saúde, há uma crescente dificuldade de estabelecer a comunicação com a família.

A partir destas constatações, e da consciência do conjunto de aspectos que convergem no processo comunicacional, faz-se necessário trabalhar estas questões com as equipes que atuam na UTIP, pois o efeito desta comunicação é recursivo, ou seja, o impacto da comunicação volta para o próprio profissional, gerando situações de estresse, angústia e isolamento, culminando em um processo iatrogênico da sua capacidade de cura, no qual se coloca diretamente em "xeque" sua habilidade profissional. 
Outro aspecto a ser apontado, decorrente da análise dos dados, é a questão da dupla vinculação das mensagens, presente no processo da comunicação, que pode gerar mais angústia e incerteza na família, e que, segundo Watzlavik et al. (1973), seria o processo de anulação da informação presente, tanto no conteúdo de uma mensagem, como na metacomunicação. Assim, as famílias podem receber mensagens diferentes, tanto em termos de conteúdo, como da metacomunicação, em que uma anula o significado da outra, gerando um impasse no processo hermenêutico apontado anteriormente, pois a família se defronta com o árduo trabalho de decodificar a ambigüidade da comunicação. Nos seguintes exemplos verifica-se esta situação:

... ou é certo ou éerrado. Ou todo mundo fala a mesma coisa, ou espera o fim. Porque se uns dez médico faz eu fazer o mesmo tratamento e de repente os dez falam coisas diferentes, e daí, a gente vai pensar o quê?... ou é grave, ou não é....

... eles falaram pra nóis uma coisa que não tem cabimento. Um dizuma coisa, outro outra... elesfalaram que o problema queela tem éuma parte ruim minha e da mulher... eseelesfalaram isso pránóis, nóisacreditemo né? imagine... médico é médico... e agora vem outra médica edizquenão tem nada a vercomnóis... o genético veio dela mesmo. Então a gente não sabe... a gente fica perdido né?" e continua “... uns dão esperança, outros não dão...então dizsim ou não deuma vez... quea gente já espera daí (pai de Mirela).

Às vezes, o conteúdo não explicita tudo 0 que se quer falar, deixando em aberto o processo da metacomunicação, tal como no exem plo abaixo:

... esses dias eu conversei com uma médica ali, nem sei como é o nome dela, ela tava trabalhando de noite, eu queria conversar com ela, ver seia sairoutro dia a cinurgia, daí ela tinha pegado plantão... daíela conversou comigo, saiu pra fora etava só eu efalou pra mim queera pra rezar quea Luana descansasse, que ela vai sofrer muito ainda se ela for sair dessa... que ela vai tá fazendo hemodiálise, queo rim dela parou... então seela sair daqui, ela vai sofrer muito ainda...então queeu rezequeDeus dêo descanso pra ela... mesma coisa a Dra. “S"também falou...queDeus desse o descanso pra ela, era melhor... vai sofrer muito... então a gentefica assim... pra gentechegaredizer: “Deus, dêo descanso pra ela..." a gente como pai nunca vai ter essa coragem... então só dizer que ela não sofra, não sofra... (pai de Luana).
Desta forma, ressalta-se a importância de resgatar junto à equipe a relevância dos processos de comunicação em situação de doença, principalmente no contexto da UTIP, pois muitos profissionais ficam atentos ao conteúdo da sua comunicação, considerando a gravidade dos casos que esta unidade atende, mas não dão a devida importância à forma pela qual as informações são passadas. Assim, seria importante refletir junto a estes profissionais sobre todo o percurso e todas as mudanças de estrutura que uma família sofre para manter uma criança internada em uma unidade, que, porsi só, é geradora de significad os associados à morte.

O impacto da internação nas relações familiares não fica evidente para os profissionais no cotidiano de uma UTIP, devido a uma série de fatores, tais como a especificidade das atividades, a formação profissional e questões pessoais dos integrantes da equipe, que, muitas vezes, negam este aspecto, mesmo sem perceber, para poderem dar conta das exigências de seu papel profissional. Considera-se que trazer isto à tona pode promovera compreensão da vivência e dos sentimentos das famílias, facilitando o processo comunicacional.

Acredita-se, assim, que as unidades temáticas descritas desvelam as relações implícitas da comunicação, que ficam camufladas por resistências psicológicas e sentimentos gerados por uma situação de crise, proporcionando um entendimento mais profundo do processo comunicacional em UTIP.

\section{Considerações Finais}

Destacam-se as seguintes conclusões, após a realização deste trabalho: a) verificou-se a presença de uma trama comunicacional no processo de comunicação entre equipe de saúde e família, a qual afetava decisivamente o processo interacional no contexto de UTIP, que, por sua vez, tinha uma repercussão direta na qualidade do trabalho dos profissionais e no maior ou menor sofrimento emocional da família; b) evidenciou-se a necessidade de a equipe estar atenta à congruência entre a mensagem digital e a analógica, devido à família estar sempre atenta às pistas comunicacionais, as quais, por sua vez, sustentavam todo um processo hermenêutico ou de interpretação, por parte da mesma, seja a partir do estado da criança internada, ou das ações da equipe; ec) observou-se que a metacomunicação esteve 
presente nas comunicações da equipe, aumentando 0 estresse familiar, assim como mensagens com dupla vinculação, gerando desconfirmação das mensagense desconcerto nas famílias.

Acredita-se que tornar visíveis os processos comunicacionais que se estabelecem a partir da internação de uma criança em UTIP possibilita instrumentalizar a equipe de saúde no sentido de manter uma comunicação simétrica, repassando informações coerentes com o estado de saúde da criança.

Neste sentido, acredita-se que a postura interdisciplinar possibilita a escuta das diferentes vozes dos profissionais nas instituições de saúde, contribuindo para tornar o momento de contato com a família menos tenso e propiciador de uma comunicação mais efetiva, fazendo com que a família sinta-se mais segura e a relação com a equipe se fortaleça.

A postura interdisciplinar também propicia uma maneira mais complexa de compreensão dos problemas, e possibilita aos profissionais compartilharem as dificuldades suscitadas pelo contexto da UTIP. A interdisciplinaridade permite a integração dos diferentes saberes dentro da unidade, contribuindo para a comunicação equipe-família.

Considerando que as vivências da família são afetadas e afetam a vivência do profissional de saúde dentro da unidade, outra proposta de intervenção poderia ser a criação de um espaço para que os profissionais da saúde pudessem trocar experiências, dificuldades e sentimentos despertados a partir do trabalho na UTIP, ou mesmo, criar um serviço de atendimento terapêutico individual dentro da instituição hospitalar, voltado para médicos e enfermeiros que são expostos a situações limítrofes durante grande parte do seu dia de trabalho. A partir do reconhecimento dos seus próprios sentimentos e dificuldades, o profissional pode estar instrumentalizado para estabelecer uma comunicação mais afetiva e menos mecânica com as famílias atendidas.

Para que exista um processo de reflexão, deveria ser rotina de uma equipe de UTIP encontros mensais ou quinzenais, nos quais se pudesse acolher os novos membros da equipe, assim como trazerà tona o enfrentamento de cada um e dos dilemas humanos vivenciados no cotidiano, percebendo suas possibilidades e limitações. Isto éo substrato principal para o desenvolvimento de uma postura interdisciplinar em uma equipe, no sentido de superação da diferenças, e na busca de construções conjuntas para o enfrentamento das situações.

\section{Referências}

Aragão, C. P., Weiss, E. M. G., \& Aquino, M. D. W. (1993). Conhecimento e práticas de saúde da família da criança hospitalizada: um estudo exploratório.Texto Contexto,2 (2), 7-22.

Bardin, L. (1977). Análise de conteúdo. Lisboa: Edições 70.

Board, R., \& Ryan-Wenger, N. (2002). Long-term effects of pediatric intensive care unit hospitalization on family with young children. Heart \& Lung, 31(1), 53-66.

Board, R., \& Ryan-Wenger, N. (2003). Stressor and stress symptoms of mother with children in the PICU. J ournal of Pediatric Nursing, 18(3), 195-202.

Borges, K. M. K., Cosmos, M., Figueiredo, J. H., \& Vianna, R. (2004). Palavras duras em voz de veludo...: o valor da comunicação da equipe com a família. Revista Brasileira deTerapia Intensiva, (Suplemento I), 56.

Bousso, R. S. (1999). Buscando preservar a integridade da unidade familiar: a família vivendo a experiência de ter um filho na UTI Pediátrica. Tese de doutorado não-publicada, Escola de Enfermagem, Universidade de São Paulo.

Bousso, R. S., \&Angelo, M. (2003). The Family in the Intensive Care Unit: living the Possibility of Losing a Child.J ournal of Family Nursing, 9 (2), 212-221.

Bowen, M. (1991). De la familia al individuo: la diferenciación del símesmo en el sistema familiar. Barcelona:Paidós Ibérica.

Crepaldi, M. A. (1999). Bioética e interdisciplinaridade: direitos de pacientese acompanhantes na hospitalização. Paidéia, 9 (16), 89-94.

Fiese, B. H., \& Bickham, N. L. (1998). Qualitative inquiry: an overview for pediatric psychology. Joumal of Pediatric Psychology, 23 (2), 79-86.

Gauderer, E. C. (1987). A criança, a morte e o luto. Jornal de Pediatria, 62 (3), 82, 85-86, 89-90.

Klüber-Ross, E. (1996). Sobre a morte e o morrer. São Paulo: Martins Fontes.

McDaniel, S. H., Hepworth, J., \& Doherty, W. J. (1994). Terapia familiar médica: um enfoque biopsicossocial às famílias com problemas de saúde. Porto Alegre: Artes Médicas.

McGoldrick, M., \&Walsh, F. (1998). Um tempo para chorar: a morte e o ciclo de vida familiar, In $\mathrm{F}$. Walsh $\& \mathrm{M}$. McGoldrick. Morte na família: sobrevivendo às perdas (pp.56-75). Porto Alegre: Artes Médicas.

Meleiro, A. M. A. S. (1998). Suicídio entre médicos e estudantes de medicina. Revista da Associação Médica Brasileira, 44 (2), 135-140. 
Miles, M. S., Burchinal, P., Holditch-Davis, D., Brunsse, S., \& Wilson, S. M. (2002). Perceptions of stress, worry, and support in black and white mothers of hospitalized medically fragile infants. J ournal of Pediatric Nursing, 17 (2), 82-88.

Mitchell, M. L., Courney, M., \& Coyer, F. (2003). Understanding uncertainty and minimizing families'anxiety at the time of transfer from intensive care. Nursing and Health Sciences, 5(3), 207-217.

Moré, C. L. O. O., \& Macedo, R. S. M. (2006). A Psicologia na comunidade:uma proposta deinterven ção. São Paulo:Casa do Psicólogo.

Nieweglowski, V. H. (2004). Unidade de terapia intensiva pediátrica: vozes e vivências da família. Dissertação de mestrado não-publicada, Programa de Pós-Graduação em Psicologia, Universidade Federal de Santa Catarina, Florianópolis.

Noyes, J. (1998). A critique of studies exploring the experiencies and needs of parents of children admitted to paediatric intensive care units. Journal of Advanced Nursing, 28(1), 134-141.
Noyes, J. (1999). The impact of knowing your child is critically ill: a qualitative study of mother's experiences. Journal of Advanced Nursing, 29(2), 427-435.

Rolland, J . (2001). Doença crônica e o ciclo de vida familiar. In B. Carter \& M. E. McGoldrick. Asmudanças no ciclo de vida familiar: uma estrutura para a terapia familiar (pp.373-391). Porto Alegre: Artes Médicas.

Spear, M. L., Leef, K., Epps, S., \& Locke, R. (2002). Family Reaction During Infants' Hospitalization in the Neonatal Intensive Care Unit. American J ournal of Perinatology, 19 (4), 205-213.

Watzlawick, P., Beavin, J. H., \& Jackson, D. (1973). Pragmática da comunicação humana: um estudo dos padrões, patologias e paradoxos da interação (9a.ed.) São Paulo: Cultrix.

Recebido em: 30/8/2006

Versão final reapresentada em:5/3/2007

Aprovado em: 9/5/2007 